\title{
Quality improvement model to ensure effective communication during Head and Neck multidisciplinary meetings
}

\author{
Manuela Cresswell \\ ENT ST5 South West Peninsula \\ Student Healthcare Management, Leadership and Innovation MSc.
}

UNIVERSITY OF PLYMOUTH

Background:

Multi-disciplinary Meetings (MDM) are instrumental in the management of Head and Neck (H\&N) cancer and are considered best practice. ${ }^{1-5}$

Communication failures account for up to $70 \%$ of adverse events in healthcare. ${ }^{6}$ Leadership and human factors are fundamental to ensure good communication in an environment of highly complex information where lifechanging decisions are made. ${ }^{7}$

\section{Objectives:}

To propose a model for improving communication in $\mathrm{H} \& \mathrm{~N}$ MDM based on current evidence to minimise human error.

Methods: Review of the literature and proposal of quality improvement model.

\section{Results:}

The review of the literature highlighted:

- The Calman-Hine report on the structure and organisation of cancer services in England and Wales introduced the necessity to adopt Multidisciplinary Team (MDT) working. ${ }^{8}$ This report was followed by similar reviews in the rest of UK 9

Improved patient outcomes

Prolonged survival rates

Better staging accuracy

Increased adherence to clinical practice guidelines

Reduced time to treatment

Increased recruitment into clinical trials

Enhanced educational opportunities

Better job satisfaction and psychological wellbeing in health professionals

\section{Communication standards of MDT practice set out in the literature}

MDTs should ensure that accurate and complete data on cancer staging, management and outcomes are recorded. 3,11

"Recording cancer site and accurate stage is a key medical responsibility, with best practice suggesting that this should be clearly documented and captured at the MDT"12

Good communication between levels of care and data collection. ${ }^{1}$

Good leadership of MDT is crucial for effective teamwork and enables successful communication during MDM. 7
A 3-step model is proposed:

1.Designated leader for MDM.

- The leader will be chosen by MDT members and can be any member if the team. A survey of MDT members in the UK showed that they believe the qualities of a good MDT leader are being calm, strong, firm, having good communication skills and ensuring enforcement of clinical decision making. ${ }^{13}$ These qualities would be desirable for the role.

- The role of the MDT leader will encompass:

- Chairing and timekeeping MDM on weekly basis.

- Inspire and encourage mutual respect and participation of team members.

- Coordinating and overseeing steps 2 and 3 of this model.

2. Key Patient Information (KPI) checklist to improve communication and reduce human error.

\begin{tabular}{|c|c|c|c|c|}
\hline \multicolumn{2}{|l|}{ Patient information } & \multicolumn{2}{|l|}{ Current pathology } & Management strategr \\
\hline -Name & $\square$ & -Clinical presentation & $\square$ & - Further investigations $\square$ \\
\hline - Hospital number & $\square$ & -Investigations & & required? \\
\hline -Date of birth & $\square$ & - Clinical & $\square$ & -Curative/Palliative \\
\hline - Comorbidities & $\square$ & - Radiology & $\square$ & - Treatment alternatives $\square$ \\
\hline -Performance status & $\square$ & - Histology & $\square$ & - Recommended options $\square$ \\
\hline -Social support & $\square$ & - TNM classification & $\square$ & -Follow up \\
\hline & & & & $\begin{array}{l}\text { - Other considerations: } \\
\text { nutritional/psychological }\end{array}$ \\
\hline
\end{tabular}

- Adopting the KPI checklist should facilitate and signpost communication as well as easing documentation of outcomes by the MDT coordinator, as it ensures key points are covered (i.e nutritional status, DNAR status)

- The checklist should be considered a work in progress and modifications by MDT members will help tailor it to suit the local service. It could be electronic or in paper form.

3. Team development and human factors training. Effective interaction in H\&N MDM between team members is required to agree recommendations about management of patients. ${ }^{2,13}$ Raising the team's awareness of human factors should create a safer and more cohesive and rewarding work environment

Condusions:

MDT working is standard in the management of $\mathrm{H} \& \mathrm{~N}$ cancer. Leadership, team development and human factors should not be overlooked in the context of MDM. We suggest a model tailored to H\&N MDM that incorporates a clear leadership role, a structured communication tool to signpost key information and reduce human error.

1. Department of Health. Manual for cancer services 2004. London: Department of Health; 2004.

2. Licitra L, Keilholz U, Tahara M, Lin JC, Chomette P, Ceruse P, et al. Evaluation of the benefit and use of multidisciplinary teams in the treatment of head and neck cancer. Oral Oncology. 2016;59:73-9.

3. Friedland PL,Bozic B, Dewar J,Kuan R, Meyer C,Phillips M. Impact of multidisciplinary team management in head and neck cancer patients. British Journal of Cancer. 2011; 104(8): 1246-8.

4. National Institute for Health and Care Excellence. Improving outcomes in head and neck cancer. London: NICE; 2004.

5. Prades J, Remue E, van Hoof E, Borras JM. Is it worth reorganising cancer services on the basis of multidisciplinary teams (MDTs)? A systematic review of the objectives and organisation of MDTs and their

impact on patient outcomes. Health Policy. 2015;119(4):464-74.

6. Group of WHO Patient Safety. Human factors in patient safety review of topics and tools, report for methods and measures working. Geneva: Group of WHO Patient Safety; 2009.

7. National Cancer Action Team. The characteristics of an effective multidisciplinary team. London: National Cancer Action Team; 2010.

8. Expert Advisory Group on Cancer. A policy framework for commissioning cancer services: a report to the chief medical officers of England and Wales. London: Department of Health; 1995.

9. Fleissig A, Jenkins V, Catt S, Fallowfield L. Multidisciplinary teams in cancer care: are they effective in the UK? Lancet Oncology. 2006;7(11):935-43.

10.Tattersall MH. Multidisciplinary team meetings: where is the value? Lancet Oncology. 2006;7(11):886-8.

11. Birchall M, Bailey D, King P. Effect of process standards on survival of patients with head and neck cancer in the south and west of England. British Journal of Cancer. 2004;91 (8):1477-81.

12. Health and Social Care Information Centre, National Head and Neck Cancer Audit 2014. Leeds: Clinical Audit Support Unit, Health and Social Care Information Centre; 2015.

13.National Cancer Action Team. Multidisciplinary team members' views about MDT working: Results from a survey commissioned by the National Cancer Action Team. London: National Cancer Action Team; 